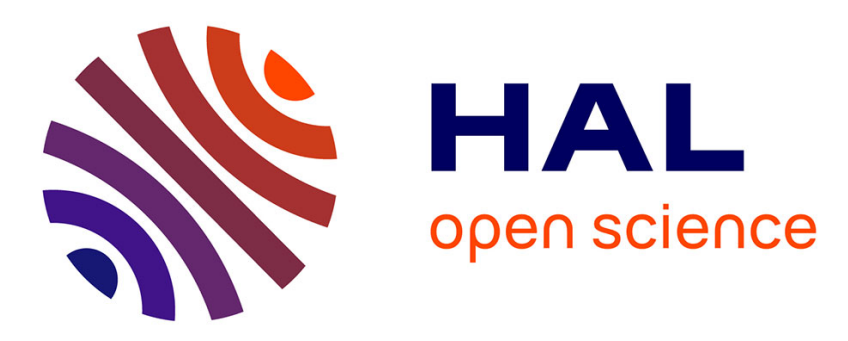

\title{
Detection of High and Low States in Stock Market Returns with MCMC Method in a Markov Switching Model
}

Clément Rey, Serge Rey, Jean-Renaud Viala

\section{- To cite this version:}

Clément Rey, Serge Rey, Jean-Renaud Viala. Detection of High and Low States in Stock Market Returns with MCMC Method in a Markov Switching Model. Economic Modelling, 2014, 41, pp.145155. 10.1016/j.econmod.2014.05.003 . hal-01880340

\section{HAL Id: hal-01880340 \\ https: / hal-univ-pau.archives-ouvertes.fr/hal-01880340}

Submitted on 24 Sep 2018

HAL is a multi-disciplinary open access archive for the deposit and dissemination of scientific research documents, whether they are published or not. The documents may come from teaching and research institutions in France or abroad, or from public or private research centers.
L'archive ouverte pluridisciplinaire HAL, est destinée au dépôt et à la diffusion de documents scientifiques de niveau recherche, publiés ou non, émanant des établissements d'enseignement et de recherche français ou étrangers, des laboratoires publics ou privés. 


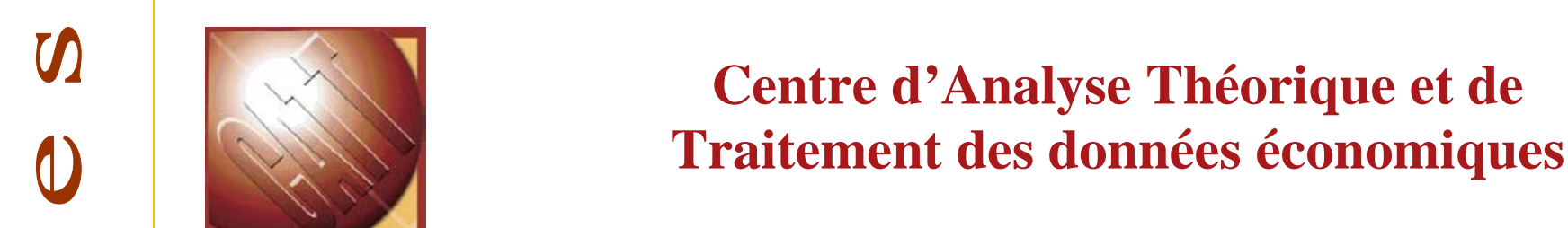

0

CATT WP No. 11

July 2013

DETECTION

OF HIGH AND LOW STATES IN STOCK MARKET RETURNS WITH MCMC METHOD IN A MARKOV SWITCHING MODEL

Clément REY

Serge REY

Jean-Renaud VIALA 


\title{
Detection of High and Low States in Stock Market Returns with MCMC Method in a Markov Switching Model
}

\author{
Clément Rey \\ CERMICS-École des Ponts Paris Tech \\ reyc@cermics.enpc.fr \\ 6 et 8 avenue Blaise Pascal, Cité Descartes - Champs sur Marne \\ 77455 Marne la Vallée Cedex 2 - France \\ Serge Rey \\ CATT-UNIV PAU \& PAYS ADOUR \\ serge.rey@univ-pau.fr \\ Avenue du Doyen Poplawski - BP1633, 64016 Pau Cedex - France \\ Jean-Renaud Viala \\ AMUNDI Asset Management \\ jean-renaud.viala@amundi.com \\ 90 Bd Pasteur - CS 21564 Paris Cedex 05 - France
}

May 2013 


\begin{abstract}
To detect abnormal states in stock market returns, this study considers seven indices, over an 21-year period, the Dow Jones, S\&P500, Nasdaq, Nikkei225, the FTSE100, DAX, and CAC40. Three states are possible, namely a state of high rate of return, a state of low rate of return, both with high volatility and an intermediate state with low volatility. To determine the state of the market at each date, we study the returns using Markov Chain Monte Carlo method (Metropolis-Hastings algorithm). Then at a second time, using a Cramer's coefficient, we deduce association coefficients or "correlations" among the different states of the major stock exchange markets around the world. First, the associations were globally stronger during the subprime crisis than during the dot-com bubble period. Second, among European markets the Cramer's V is higher regardless of the period. Third, the associations between the Nikkei and the other markets indices are systematically lower, indicating the relative disconnection of the Japanese market.
\end{abstract}

\title{
1 Introduction
}

The availability of high frequency data for financial series and the development of mathematical and computer tools in recent decades support renewed research into the behavior of financial asset prices. The study of the statistical properties of asset returns, which are essential for managing portfolios of assets, is a vital component of the domain [1]. Several research areas thus have been explored including the problems of measuring volatility/risk assets, the phenomena of bubbles and financial crisis, the measures of abnormal returns, correlations or dependencies between assets and/or markets and contagion effects.

A particularly important question in financial analysis is how the volatility and the trend of stock prices behave. Such forecasts are essential to determinate options prices, portfolio optimization among others.

Some authors mainly focused on the mean return, we call also drift among a period. Since publications by Brown and Warner [2], [3], many articles sought to the measure security price performance, and particularly assess abnormal returns. Generally, the return of a security/stock is abnormal if it differs from a "normal" return, that is, from a particular benchmark. This benchmark may be a simple mean return, a return deduced from a CAPM model or a multi-factor model (e.g. the three-factor Fama and French model [17], [25]). However, these approaches face limitations, in that they require a risk-free return to estimate the normal return. In reality though, situations such as the actual debt crisis in Europe complicate the choice of a risk-free return. In addition, these methods essentially determine the abnormal returns of a security/stock. It also may be interesting to estimate abnormal returns of a market. We therefore propose another method to estimate abnormal returns that can be applied to both the return on a security and at the return on a market portfolio.

Many other authors focused on the behavior of the volatility. The first models are 
based on autoregressive conditional heteroscedastic processes (ARCH), which should provide better measures of the dispersion and volatility of assets prices than a simple standard deviation [10], [1]. Some authors also are interested in modeling the tails of the distribution of returns (extreme values), such that they isolate the effects of shocks to the natural tendency of markets [8]. By extension, other studies focus on correlations/dependencies among stock returns, seeking possible crossmarket spillover effects in financial markets. Such work has taken several forms, from the analysis of contagion effects [20], [19], to the study of copulas [11].

However a simple observation shows that there are sequences of high and low volatilities. To take into account these facts, some authors introduce markov-switching parameters to ARCH models [15], [4], while Dueker [9] extended their approach to GARCH models to describe two stylized facts: conditional volatility can increase substantially (jumps) in a short time; "the stock-market volatility does not remain persistently two to three times above its normal level the same way it can persist at 30-40 percent above normal" ([9] p. 26). The standard approach considers that the parameters (one or several) in conditional volatility are subject to markov-switching, which permits to distinguish several states. Most of works retain three states, even if 4-states or 5-states models can be estimated. In [18] (p. 442), using a 4-states model, the authors conclude that the last state represents "only one observation that pertains to this regime ... the 1987 October crash of the stock market". In the standard case of three states, we generally distinguish: a state of high volatility, a state of low volatility and a medium state. If the first works use Maximum-Likelihood (ML) estimation, [18] adopt a MCMC method to estimate a time series model with autoregressive conditional heteroscedasticity and changes in regime.

The present study advances in the line of [13] [14], with the objective of revealing "abnormal" situations. Our main issue in modeling is how we define an "abnormal" return and according to which features we classify them. We highlight distinct regimes in the stock market returns based on the volatility but also on the drift.

Consequently, our research differs from the previous works as we seek to reveal switching not only in stock returns volatility but in drifts and volatility together. We focus on detecting the abnormal returns following [22] and [13]. We assume three states are possible. State 1 and 3 are considered to reflect periods of high volatility and respectively high and low drift while state 2 refers to periods with standard drift and low volatility. For instance the market is in state 1 during a bubble period and similarly in state 3 during a crisis period. However the controversy is not true. In a risk-on risk off approach, the transition itself to level 1 or 3 from the intermediate level is useful information since it characterizes a period of high uncertainty.

Meanwhile, following work by Black, Scholes and Merton in the 1970s, widespread uses of diffusion models for pricing options have been observed [12]. The use of variants of these models, assuming that the asset price is driven by an Ito process, involving a Brownian part, is also generalized for the study of returns.

In our study we consider that the return follows a diffusion process with a drift and a 
volatility (covariance in multidimensional case) parameters. Moreover given the state of the market we assume those parameters are constants. Obviously they change from one state to another. Following this purpose we present a Bayesian approach based on a MCMC method/algorithm to estimate the parameters of the Markov switching model in each case together with the estimation of the state for each period.

We make the general assumption that the current price contains all the information such that the future price depends on the past only through the current observation. This assumption is necessary in finance for computing, for example, the option price. The other assumption we make pertains to the independence of returns, which is required to estimate the parameters of the model applying the Central Limit Theorem. Thus we model prices using a classical Black \& Scholes diffusion for each state, an approach that is very convenient, because we can identify for each state its deterministic drift part and its random component, according to the volatility of the returns. Moreover the changing states from one date to another represent a transition matrix. The estimation relies on a Bayesian approach. In turn with this method, we can assess the value of the parameters while there is still liberty in them through observations made on the market.

We study the stock market returns of several developed countries. To do so, we being by detailing our model in Section 2, followed by MCMC method and the algorithms used in Section 3. Section 4 presents an application to weekly data for the Dow Jones, Nasdaq, S\&P 500, Nikkei, FTSE, CAC 40, and Dax market indexes, over the period 1991-2011. Section 5 concludes.

\section{The market model}

We assume $d$ assets that generate $d$ risk sources. Let $T>0$ be a time-finite horizon. We consider the $d$-dimensional Brownian motion $\left(W_{t}\right)_{t \in[0, T]}$ and $(\Omega, \mathcal{F}, \mathbb{P})$ the filtered probability space at stake, with $\Omega$ the set of events, $\mathcal{F}=\left(\mathcal{F}_{t}\right)_{t \in[0, T]}$, the natural Brownian filtration defined by $\mathcal{F}_{t}=\sigma\left(W_{s} ; s \leqslant t\right)$. $\mathcal{F}_{t}$ contains all the information of the market up to date $t$. Originally the Black and Scholes model for the asset prices process denoted $\left(S_{t}\right)_{t \in[0, T]}$, with drift $b \in \mathbb{R}$, standard deviation $\sigma>0$ and $d=1$ has been defined by

$$
d S_{t}=S_{t}\left(b+\frac{\sigma^{2}}{2}\right) d t+S_{t} \sigma d W_{t}
$$

with $S_{0}>0$. Then for a given $s \in[0, T]$, the return process between dates $s$ and $t$, denoted $(r(s, t))_{t \in[s, T]}$, and defined by $r(s, t)=\ln \left(\frac{S_{t}}{S_{s}}\right)$ satisfies

$$
d r(s, t)=b d t+\sigma d W_{t}
$$

with $r(s, s)=0$. Since $b$ and $\sigma$ are fixed constants we have, for $t \geqslant s$, 


$$
r(s, t)=b(t-s)+\sigma\left(W_{t}-W_{s}\right)
$$

One may notice that $W_{t}-W_{s}$ follows the normal distribution with mean 0 and variance $t-s$. Moreover it is independent from the sigma algebra $\mathcal{F}_{s}$, that is all the information contained in the market up to the date $s$. Now we present our model which is a variant from this model. This variant is multidimensional and $b$ and $\sigma$ depend on the time. Moreover the couple $\left(b_{t}, \sigma_{t}\right)$ takes its values in a set that contains three elements.

\section{The model}

We denote $\left(S_{t}\right)_{t \in[0, T]} \in\left(\mathbb{R}_{+}^{*}\right)^{d}$ as the $d$-dimensional, strictly positive, underlying assets process. We consider that $S$ has the following form,

$$
\forall i \in\{1, \cdot, d\} \quad d S_{t}^{i}=S_{t}^{i}\left(b_{t}^{i}+\frac{1}{2} \sum_{j=1}^{d}\left(\sigma_{t}^{i j}\right)^{2}\right) d t+S_{t}^{i} \sum_{j=1}^{d} \sigma_{t}^{i j} d W_{t}^{j}
$$

with $b_{t} \in \mathbb{R}^{d}, \sigma_{t} \in \mathbb{R}^{d \times d} \mathcal{F}_{t}$-measurable. We define the log return as :

$$
\forall 0 \leq s<t \leq T, i \in\{1, \cdot d\}, \quad r^{i}(s, t)=\ln \left(\frac{S_{t}^{i}}{S_{s}^{i}}\right) \in \mathbb{R}
$$

For a given $s \geqslant 0$, the Ito formula implies,

$$
\forall t \geqslant s, \quad d r^{i}(s, t)=b_{t}^{i} d t+\sum_{j=1}^{d} \sigma_{t}^{i j} d W_{t}^{j}
$$

We notice that for all $t \leqslant t^{\prime}<t^{\prime \prime}$, then $r\left(t, t^{\prime \prime}\right)=r\left(t, t^{\prime}\right)+r\left(t^{\prime}, t^{\prime \prime}\right)$. Now we specify the form of the process $\left(b_{t}, \sigma_{t}\right)_{t \in[0, T]}$. We assume this couple can take three different constant values that is $\left(b_{t}, \sigma_{t}\right) \in\left\{\left(b_{1}, \sigma_{1}\right),\left(b_{2}, \sigma_{2}\right),\left(b_{3}, \sigma_{3}\right)\right\}$. We denote the discrete random Markov process $\left(Y_{t}\right)_{t \in[0, T]} \in\{1,2,3\}$ that specifies the state of the market. We define

$$
b_{t}=b_{Y_{t}}, \quad \sigma_{t}=\sigma_{Y t} .
$$

In that case (4) and (5) are well defined and have a unique solution.

Our purpose is to distinguish two states with low information inflow and low or high returns, labeled 1 and 3, and an intermediate regime, the second one, with lower variance and standard return. Following this idea we assume : $\forall j \in\{1, \cdots, d\}, b_{1}^{j}<b_{2}^{j}<b_{3}^{j}$ and for the matrix norm $\|$.$\| we have, \left\|\sigma_{1}\right\|,\left\|\sigma_{3}\right\|>\left\|\sigma_{2}\right\|$.

We define $\left(Y_{t}\right)_{t \in[0, T]}$ as a piecewise constant process that can jump only on the time grid $\left\{t_{0}, \cdots, t_{n-1}\right\}$ with $t_{k}=\frac{k T}{N}$. We have then $Y_{t}=Y_{t_{k}}$ for all $t \in\left[t_{k}, t_{k+1}[\right.$. In that 
case we denote by $\mathcal{P} \in] 0,1[3 \times 3$, its transition matrix. $\mathcal{P}$ gives the probability of being in a state at the next date, conditional on the current state, that is,

$$
\forall k \in\{1, \ldots, n-1\}, \quad \mathbb{P}\left(Y_{t_{k+1}}=j \mid Y_{t_{k}}=i\right)=\mathcal{P}^{i j} .
$$

We notice that the diagonal of $\mathcal{P}$ gives the probability to stay in the current state. We denote $\left.\omega_{t} \in\right] 0,1\left[^{3}\right.$ the law of the random variable $Y_{t}$ such that $\mathbb{P}\left(Y_{t}=i\right)=\omega_{t}^{i}$. We have then

$$
\forall k \in\{1, \ldots, n\}, \quad \omega_{t_{k}}=\omega_{0} \mathcal{P}^{k}
$$

Its stable law is given by the solution of $\omega=\omega \mathcal{P}$. This law gives the probability of each state once equilibrium is reached. In such case $\omega^{1}+\omega^{3}$ is the probability that the market is in a period of high volatility while $\omega^{2}$ is the one of being in the intermediate regime. Heuristically we want $\omega^{2}$ to be the highest probability.

\section{The return process}

Since $\left(Y_{t}\right)_{t \in[0, T]}$ is a piecewise constant process, then $b_{t}$ and $\sigma_{t}$ are constant for $t \in\left[t_{k}, t_{k+1}[\right.$ and we can write the exact decomposition of the diffusion of the return process on time grid $\left\{t_{0}, \cdots t_{N}\right\}$ as :

$$
r\left(t_{k+1}, t_{k}\right)=b_{Y_{t_{k}}}^{i}\left(t_{k+1}-t_{k}\right)+\sum_{j=1}^{d} \sigma_{Y_{t_{k}}}^{i j}\left(W_{t_{k+1}}^{j}-W_{t_{k}}^{j}\right) .
$$

Summing over $k$, we obtain,

$$
\begin{aligned}
& \forall l_{1}<l_{2} \in\{1, \cdots, n\}, \\
& r^{i}\left(t_{l_{1}}, t_{l_{2}}\right)=\sum_{k=l_{1}}^{l_{2}-1} b_{Y_{t_{k}}}^{i}\left(t_{k+1}-t_{k}\right)+\sum_{k=l_{1}}^{l_{2}-1} \sum_{j=1}^{d} \sigma_{Y_{t_{k}}}^{i j}\left(W_{t_{k+1}}^{j}-W_{t_{k}}^{j}\right) .
\end{aligned}
$$

We notice that the Brownian increments $\left(W_{t_{k+1}}^{j}-W_{t_{k}}^{j}\right)_{(k, j) \in\{0, \cdot, n-1\} \times\{1, \cdot, d\}}$ form a sequence of independent and identically distributed random variable following a centered normal distribution with variance $\frac{T}{n}$.

Remark 2.1. From the independence of Brownian increments and properties on $\left(Y_{t}\right)_{t \in[0, T]}$ we can deduce that $S, b_{Y}$, and $\sigma_{Y}$ are Markov processes. We also notice that for all $s, t, s^{\prime}, t^{\prime}$ on time grid $\left\{t_{0}, \cdots, t_{n}\right\}$, with $s<t \leqslant s^{\prime}<t^{\prime}$, then $r(s, t)$ is independent from $r\left(s^{\prime}, t^{\prime}\right)$.

\section{Estimation of the parameters}

\subsection{Bayesian approach}

We define by $\theta=\left(\left(b_{1}, \sigma_{1}\right),\left(b_{2}, \sigma_{2}\right),\left(b_{3}, \sigma_{3}\right), \mathcal{P}, Y_{0},\left(Y_{t_{k}}\right)_{k \in\{0, \cdot, n-1\}}\right)$ the set of parameters to estimate regarding the observations. We denote by $\mathcal{S}_{n}$ the set of observations until 
$t_{n}$. To do so, we use a Bayesian approach. This method consists of establishing a distribution prior law, denoted $\nu$, to $\theta$. We then compute the most likely law, or posterior law, conditional to the observations : $\nu_{\mid \mathcal{S}_{n}}=\mathbb{P}\left(\theta \mid \mathcal{S}_{n}\right)$. Thus, we grant a liberty to the values to be selected for the parameter, though we still guide the calibration with respect to the law, $\nu$, we choose for $\theta$, and the parameters we apply to this law. Once we know the posterior law we estimate $\theta$ applying a Monte Carlo algorithm and the estimator is given by

$$
\widehat{\theta}=\frac{1}{N} \sum_{i=1}^{N} \theta_{i}
$$

with $N$ the number of Monte Carlo steps and $\left(\theta_{i}\right)_{i \in\{1,, N\}}$ a sequence of independent and identically distributed random variables with law $\nu_{\mid \mathcal{S}_{n}}$.

We expose the prior distribution chosen for the different processes followed by the parameters of the equation (11). First of all we assume that $b_{i}$ and $\sigma_{i}$ are independent random variable. We rely on the following notations:

$$
\left\{\begin{array}{l}
b_{i} \sim \mathcal{N}\left(\mu_{i}, \Sigma_{i}\right) \\
\left(\sigma_{i} \sigma_{i}^{*}\right)^{-1} \sim W_{p}\left(\alpha_{i}\right) \\
(\mathcal{P})_{i}=\left(\mathcal{P}^{i 1}, \mathcal{P}^{i 2}, \mathcal{P}^{i 3}\right) \sim \operatorname{Dir}\left(\zeta_{i, 1}, \zeta_{i, 2}, \zeta_{i, 3}\right) \\
Y_{0} \sim \mathcal{U}\{1,2,3\} \\
\forall k \in\{0, \cdots, n-1\}, i \in\{1,2,3\}, \mathbb{P}\left(Y_{t_{k+1}}=i \mid Y_{t_{k}}, \mathcal{P}\right)=\mathcal{P}^{Y_{t_{k}} i}
\end{array}\right.
$$

where Dir refers to a Dirichlet distribution with three liberty degrees; $W_{p}\left(\alpha_{i}\right)$ is the Wishart distribution with mean $\alpha_{i}$ and $\mathrm{p}$ degrees of freedom, and $\mathcal{U}$ refers to the discrete uniform distribution.

\section{Choice of the parameters for the prior law}

The parameters $\mu, \alpha$, and $\zeta$ will determine the likely range of values that can take $\theta$. For example, higher $\left|\mu_{1}\right|$ and $\left|\mu_{3}\right|$ imply a lower probability of their state. Indeed,

$$
\tilde{\mathcal{P}}^{i j}=\mathbb{E}\left[\mathcal{P}^{i j}\right]=\frac{\zeta_{i, j}}{\sum_{k=1}^{3} \zeta_{i, k}} .
$$

We denote $\tilde{\omega}$ the stable law of $\tilde{\mathcal{P}}$. We have,

$$
\begin{aligned}
\mathbb{E}\left[b_{t_{k}}\right] & =\mathbb{E}\left[\mathbb{E}\left[b_{Y_{t_{k}}} \mid \omega_{t_{k}}\right]\right] \\
& =\sum_{i=1}^{3} \mathbb{E}\left[\omega_{t_{k}}^{i} \mathbb{E}\left[b_{i}\right]\right] \\
& =\sum_{i=1}^{3} \mu_{i} \mathbb{E}\left[\omega_{t_{k}}^{i}\right]=\sum_{i=1}^{3} \mu_{i} \tilde{\omega}_{t_{k}}^{i} .
\end{aligned}
$$


The same way we have $\mathbb{E}\left[\sigma_{t_{k}} \sigma_{t_{k}}^{*}\right]=\sum_{i=1}^{3} \alpha_{i}^{-1} \tilde{\omega}_{t_{k}}^{i}$. Let us denote $\bar{b}$ and $\bar{\sigma}$ the Maximum Likelihood estimators of $\mathrm{b}$ and $\sigma$. A reasonable choice of parameters could be to impose $\mu, \alpha$ and $\zeta$ such that

$$
\left\{\begin{array}{l}
\sum_{i=1}^{3} \mu_{i} \tilde{\omega}^{i} .=\bar{b} \\
\sum_{i=1}^{3} \alpha_{i}^{-1} \tilde{\omega}^{i}=\overline{\sigma \sigma^{*}}
\end{array}\right.
$$

Once we have selected these parameters, it remains to simulate the posterior law that is the prior law given the observations, and then to calculate the estimator using the formula 12. To achieve, we use a Markov Chain Monte Carlo method, and more precisely the Metropolis-Hasting algorithm.

\subsection{Markov Switching and MCMC methodology}

We recall we assume that the global asset process can switch states with respect to the evolution of the Markov chain $\left(Y_{t}\right)_{t \in[0, T]}$.

Heuristically, we try to find the best realization of this prior law that maximizes the likelihood of occurrence of the observations, and we estimate the parameters with Monte Carlo method. To obtain the posterior law, we use Metropolis-Hasting algorithm.

We do not go further in describing theoretical parametrization steps but rather refer the reader to [13]. Our purpose here is to identify different states in miscellaneous markets and their underlying common features. For example, we observe the Cramer's $\mathrm{V}$ between states identified in different markets around various periods. For this study we provide the Metropolis-Hasting algorithm applied to estimate the parameters of equation (11).

\subsection{The Metropolis-Hasting algorithm}

We do not describe this algorithm in detail because it has been well developed in prior literature. We recall simply that the retained approach relies on the use of a multiple-block Metropolis-Hastings algorithm, such that "the parameters are grouped into several distinct blocks, and then each block of parameters is updated in sequence by a Metropolis-Hastings step, conditioned on the most current value of the parameters in the remaining blocks" [6]. In other words, we have $\theta=\left(\theta_{1}, \cdots, \theta_{l}\right)$ and the posterior law of $\theta_{i}$ is the prior law of $\theta_{i}$ knowing $\mathcal{S}_{n}$ but also $\theta \backslash\left\{\theta_{i}\right\}$.

The idea of the algorithm remains the same as when $l=1$, and relies on the Bayes formula. The methodology consists in defining a Markovian transition function $f$, a sequence of independent random variables $\left(Z^{m}\right)_{m \in \mathbb{N}}$ with density probability law $x \mapsto f\left(\theta^{m}, x\right)$, and a sequence of acceptance random variables $\left(\alpha^{m}\right)_{m \in \mathbb{N}} \in\{0,1\}$ in order to define a Markov chain $\left(\theta^{m}\right)_{m \in \mathbb{N}}$ as follow

$$
\theta^{m+1}=\alpha^{m} Z^{m}+\left(1-\alpha^{m}\right) \theta^{m} .
$$


It means that $\theta^{m+1}=Z^{m} \sim f\left(\theta^{m},.\right)$ with probability $\mathbb{P}\left(\alpha^{m}=1\right)$ and $\theta^{m+1}=\theta^{m}$ with probability $\mathbb{P}\left(\alpha^{m}=0\right)$. If we choose

$$
\mathbb{P}\left(\alpha^{m}=1\right)=\frac{\mathbb{P}\left(Z^{m} \mid \mathcal{S}_{n}\right) f\left(Z^{m}, \theta^{m}\right)}{\mathbb{P}\left(\theta^{m} \mid \mathcal{S}_{n}\right) f\left(\theta^{m}, Z^{m}\right)}
$$

it implies that $\theta^{m}$, with law $\nu_{\mid \mathcal{S}_{n}}^{m}$, converges to a random variable with law $\nu_{\mid \mathcal{S}_{n}}$. We then compute the estimator with the formula (12) with $\theta_{i}=\theta^{m+i}$ when $m$ is large enough to consider that we have reached the convergence field. The acceptance probability $\mathbb{P}\left(\alpha^{m}=1\right)$ is calculated using the Bayes formula. Indeed

$$
\mathbb{P}\left(\theta \mid \mathcal{S}_{n}\right)=\frac{\mathbb{P}(\theta) \mathbb{P}\left(\mathcal{S}_{n} \mid \theta\right)}{\mathbb{P}\left(\mathcal{S}_{n}\right)}
$$

Hence,

$$
\mathbb{P}\left(\alpha^{m}=1\right)=\frac{\mathbb{P}\left(Z^{m}\right) \mathbb{P}\left(\mathcal{S}_{n} \mid Z^{m}\right) f\left(Z^{m}, \theta^{m}\right)}{\mathbb{P}\left(\theta^{m}\right) \mathbb{P}\left(\mathcal{S}_{n} \mid \theta^{m}\right) f\left(\theta^{m}, Z^{m}\right)}
$$

We give now the algorithm in our framework. First of all we give some necessary properties to ensure convergence in the Metropolis Hasting algorithm.

Definition 3.1. Let $\left(M^{m}\right)_{m \in \mathbb{N}}$ be a Markov chain. Then,

1. $M$ is reversible if : $\forall x, y \in \mathbb{R}^{n}, m \in \mathbb{N}$,

$$
\mathbb{P}\left(M^{m+1}=y \mid M^{m}=x\right) \mathbb{P}\left(M^{m}=x\right)=\mathbb{P}\left(M^{m+1}=x \mid M^{m}=y\right) \mathbb{P}\left(M^{m}=y\right) .
$$

2. $M$ is irreducible if : $\exists m_{0} \in \mathbb{N}, m_{0}>m$,

$$
\mathbb{P}\left(M^{m+m_{0}}=y \mid M^{m}=x\right)>0 .
$$

3. $M$ is aperiodic if : $\forall x, y \in \mathbb{R}^{n}, m \geq \mathbb{N}$,

$$
\operatorname{gcd}\left\{m_{0} \in \mathbb{N}^{*}, \mathbb{P}\left(M^{m+m_{0}}=y \mid M^{m}=x\right)>0\right\}=1 .
$$

Irreducibility means we can reach all states of the Markov chain with strictly positive probability. Aperiodicity signifies we cannot return to a state with regular time. It thereby avoids seasonality phenomena.

Now we expose the Metropolis-Hasting algorithm by block which is used in our study.

Proposition 3.1 (Metropolis-Hasting algorithm). Let $\mathcal{S}_{n}$ denotes the sample of $n$ observations, $N_{0}$ be the number of steps before we run Monte Carlo, $N$ be the number of Monte Carlo observations, and a prior law given by $\nu=\left(\nu_{1}, \cdots, \nu_{l}\right)$. For $x, y \in \mathbb{R}^{d}$, $j=1, \ldots, l$, we introduce $f_{j}:\left(\mathbb{R}^{d} \times \mathbb{R}^{d}\right) \rightarrow \mathbb{R}_{+}$, s.a. $\int_{\mathbb{R}^{n}} f_{j}(x, y) d y=1$, which constitutes the Markovian transition probability density function candidate for the parameters $j$, knowing $\theta \backslash\left\{\theta_{j}\right\}$. 


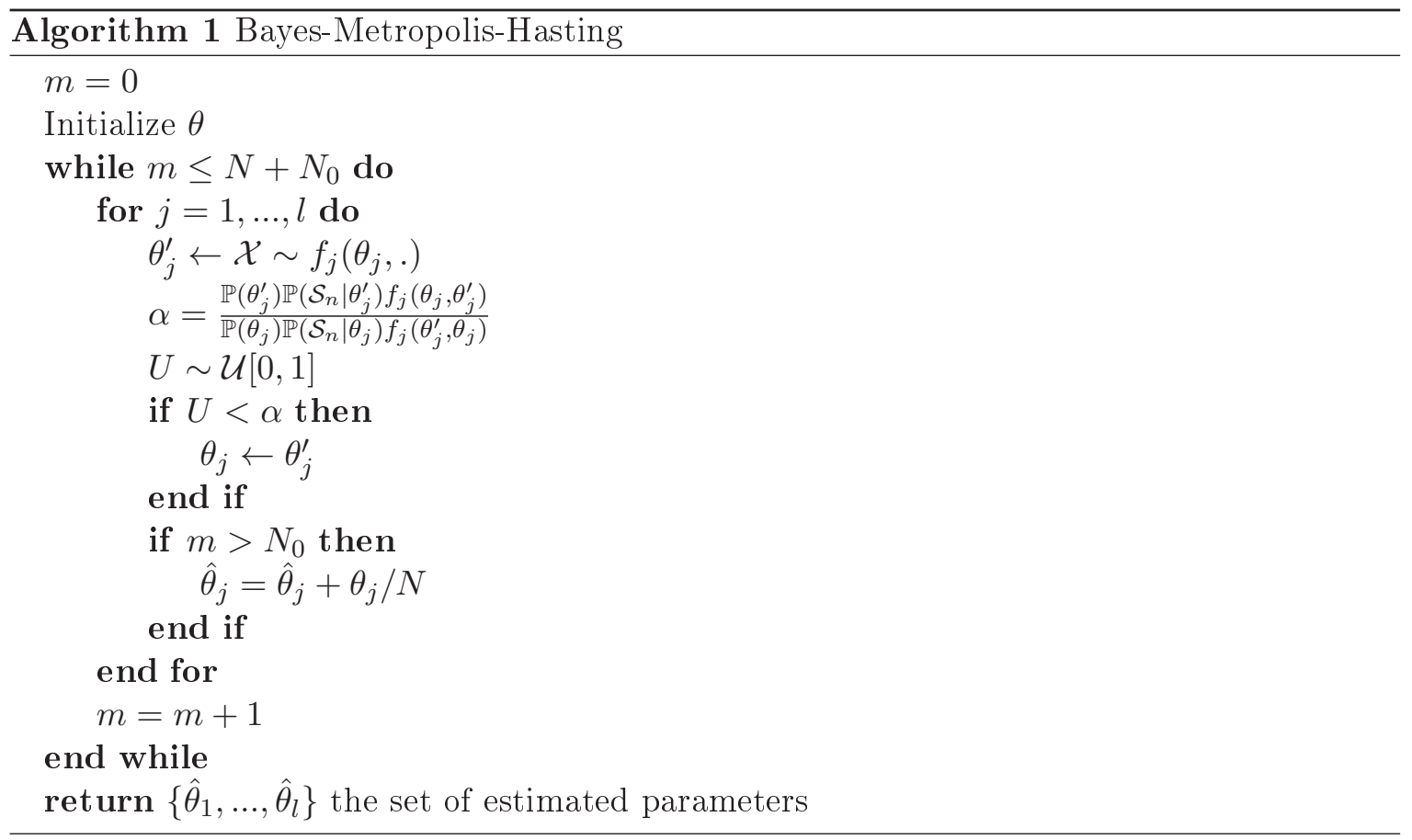

where $\mathbb{P}\left(\theta_{j}^{\prime}\right)=\nu_{j}\left(\theta_{j}^{\prime}\right)$ and $\mathbb{P}\left(\theta_{j}\right)=\nu_{j}\left(\theta_{j}\right)$.

Then, the Markov chain $\theta$ thus defined is reversible, irreducible, and aperiodic, and it converges to a random variable with law $\nu_{\mid \mathcal{S}_{n}}$. Hence, $\left\{\hat{\theta}_{1}, \ldots, \hat{\theta}_{l}\right\}$ is the Bayesian estimator of the parameters of (11) with prior law $\nu$ and observations $\mathcal{S}_{n}$.

Remark 3.1. 1. Since the state process takes discrete values, we adapt its Monte Carlo estimator at time $t_{i}$ and define:

$$
\hat{Y}_{t_{i}}=\underset{j \in\{1,2,3\}}{\operatorname{argmax}}\left\{y_{j}, y_{j}=\operatorname{Card}\left\{\left(Y_{t_{i}}\right)_{m>N_{0}}\right\}\right\}
$$

2. We estimate each block, one at a time. Furthermore, the law of a block can depend on the value of another block. The proof of the convergence for this case is given in [5].

3. If the transition density function candidate is symmetric, then

$$
\alpha=\frac{\mathbb{P}\left(\theta_{j}^{\prime}\right) \mathbb{P}\left(\mathcal{S}_{n} \mid \theta_{j}^{\prime}\right)}{\mathbb{P}\left(\theta_{j}\right) \mathbb{P}\left(\mathcal{S}_{n} \mid \theta_{j}\right)},
$$

which offers a likelihood fraction. Heuristically, we choose the more likely realization under the law $\nu_{j}$.

\subsection{Choice of the transition density functions}

We show some possible choices for the transition density candidate similar to random walks or more generally to symmetric density functions. We give a possible choice of density functions candidate for the miscellaneous parameters and recall also their prior distribution which were given in the beginning of this section. 
1. We have $b_{i} \sim \mathcal{N}\left(\mu_{i}, \Sigma_{i}\right),\left(\sigma_{i} \sigma_{i}^{*}\right)^{-1} \sim W_{p}\left(\alpha_{i}\right)$. We define the transition Markov chain as follow.

$$
\begin{aligned}
\left(\left(b_{i}\right)^{m+1},\left(\sigma_{i}\right)^{m+1}\right) & =\left(\left(b_{i}^{j}\right)^{m+1},\left(\sigma_{i}^{k j}\right)^{m+1}\right)_{k, j \in\{1, \cdot, d\}} \\
& =\left(\left(b_{i}^{j}\right)^{m}+r_{b_{i}}^{j}\left(\xi_{b_{i}}^{j}\right)^{m},\left(\sigma_{i}^{k j}\right)^{m+1}\right)
\end{aligned}
$$

with

$$
\begin{aligned}
& \left(\sigma_{i}^{k j}\right)^{m+1}=\left(\sigma_{i}^{k j}\right)^{m}+r_{\sigma_{i}}^{k j}\left(\xi_{\sigma_{i}}^{k j}\right)^{m} \\
& \left(\sigma_{i}^{k k}\right)^{m+1}=\left|\left(\sigma_{i}^{k k}\right)^{m}+r_{\sigma_{i}}^{k k}\left(\xi_{\sigma_{i}}^{k k}\right)^{m}\right|
\end{aligned}
$$

with the $N+N_{0}$ independent random variables $\left(\xi_{b_{i}}^{j}, \xi_{\sigma_{i}}^{k j}\right)^{m} \sim \mathcal{N}\left(0, I_{2}\right)$. Then

$$
f_{b_{i}^{j}}(x, y)=\mathbb{P}\left(r_{b_{i}}^{j}\left(\xi_{b^{i}}^{j}\right)_{m}=y-x\right)=f_{b_{i}^{j}}(y, x),
$$

is symmetric, and $f_{\sigma_{i} \sigma_{i} *}$ also as a combination of Normal and Wishart distributions.

2. $(\mathcal{P})_{i} \sim \operatorname{Dir}\left(\zeta_{i, 1}, \zeta_{i, 2}, \zeta_{i, 3}\right)$, where $\zeta_{i, j}$ can depend on $\left(Y_{t}\right)_{t \in\left\{t_{0}, \ldots, t_{n}\right\}} ; Y_{0} \sim \mathcal{U}\{1,2,3\}$; $Y_{t_{i+1}} \in\{1,2,3\}, \mathbb{P}\left(Y_{t_{i+1}}=j \mid Y_{t_{i}}, \mathcal{P}\right)=\left(Y_{t_{i}} \mathcal{P}\right)_{j}$. We simulate the new $(\mathcal{P})_{i}, Y_{0}$ and $Y_{t_{i+1}}$ from their prior density distributions; again, the transition density is symmetric.

\section{Application}

\subsection{Weekly stock index data}

The data in this study consist of weekly returns ${ }^{1}$, collected between January 1991 (first week) and December 2011 (third week) for seven stock indexes from developed economies: Germany (DAX), France (CAC40), the United Kingdom (FTSE100), Japan (Nikkei 225), and the United States (S\&P500, Nasdaq, and Dow Jones). Denote as the price index at time $\mathrm{t}(\mathrm{t}=1 \ldots$ 1095). For the sake of simplicity and to obtain percentage values, we define :

$$
r_{t}=100 \ln \left(\frac{S_{t}}{S_{t-1}}\right)
$$

as the compounded return for different stock indexes at time t.

Figures 1 to 7 display time-series plots for the levels and returns of markets indices. Except for the Nikkei and Nasdaq, we observe similar trends. A first rise phase of indices can be seen from early 1990s to the dot-com bubble burst in 2000. Thereafter, we have a decrease phase followed by a turn upward in 2003, which persists until the subprime crisis. This crisis reached its nadir in October 2008 with Lehman Brothers' bankruptcy. The behavior of the Nikkei index is relatively different though, in that during this period, we observe a downward trend in the stock market index. During

\footnotetext{
${ }^{1}$ E xtracted from http://finance.yahoo.com
} 
1990s, or lost decade, Japanese growth rates were very weak, with an average annual growth of per capita gross domestic product (GDP) of $0.5 \%$ [16]. This contraction followed the bursting of the stock market and real estate bubbles at the end of the 1980s.

In addition, the stock returns reveal higher volatility during the financial crisis, between 2000 and 2003 and mainly in 2007/2008. Finally, the Jarque-Bera statistic (Table 1) calculated for the stock return confirms the rejection of the null hypothesis of normality.

\section{(INSERT fig. 1-7) (INSERT table 1)}

\subsection{Estimating the states}

In Figure 8, we present the states for the stock market returns. Because we denote three possible states for the returns, we denote values of 1, 2 and 3 as low, intermediate, and high states. To derive the normalized variables, we subtract the mean and divide by the standard deviation. Several observations may be done:

1. The abnormal returns for US and European markets that is in low and high states do not appear throughout the whole period. For example, for US markets, we obtain abnormal returns during two periods: the dot-com bubble and the subprime crisis. There are few abnormal returns during the 1990s or between 2002 and 2007. It is during the subprime and euro crisis that we observe many abnormal returns for the French index; for the Dax and the CAC40, the abnormal states are fewer during the dot-com crisis.

2. The behavior of the Japanese market is very different. There are many abnormal returns during the 1990s, unlike in the other countries, and fewer abnormal returns between 2000 and 2007. We find more abnormal returns during the subprime crisis, whereas the Japanese stock market does not appear disturbed by the euro crisis.

3. In Table 2, we complete these estimations with the transition matrices for three states. In all cases, the probability of remaining in the intermediate state is very high, around 0.90 for the state and 0.97 for the states. The transition probabilities of abnormal states are lower for the Japanese market (0.22-0.23) than for other stock markets (from 0.30 to 0.45 ).

Finally, these observations can be completed by calculating of correlations across states.

(INSERT fig. 8) (INSERT table 2) 


\subsection{Measure of association between states}

An important issue for financial markets is the correlation between returns, particularly abnormal returns. Generally, cross-asset correlations may be analyzed using the covariance of returns. Covariance between two assets/market indices is the product of three terms: the volatilities of the two market indices and their correlation. Insofar as the "covariance may vary, not because the correlation between the two assets change, but simply because their individual change" [7], economists and statisticians tend to choose to estimate correlation matrices. But here, we are interested in different states of markets, represented by qualitative variables that can take the three values we have noted. Therefore, a correlation coefficient is not relevant, and we instead retain a contingency table analysis.

First, we characterize the significance of the association between states of returns using a chi-square statistic. However, a test of the null hypothesis of no association between two variables is not sufficient to quantify the strength of association. Several measures of association, analogous to correlation coefficients, appear in prior literature. We adopt the more general measure that is the Cramer's V. This coefficient is bounded between 0 and 1 , such as it equals 0 when there is no association and 1 if the association is perfect. We use $\mathrm{I}$ and $\mathrm{J}$ to denote the number of rows and columns, and $\mathrm{N}$ is the total number of events, such as the formula for Cramer's $\mathrm{V}$ is: $V=\sqrt{\chi^{2} / N \min (I-1, J-1)}$.In Table 3 , we present the association measures for states and for three periods: the global period, the dot-com bubble period (May 1994-September 2002) and the subprime and euro crisis period (July 2007-December 2011). For the whole period, we find higher coefficients, around 0.40, among European markets, i.e. FTSE, DAX and CAC indices, and lower coefficients, around 0.10-0.20, between the Nasdaq and these three European markets. When we consider the Nikkei, the null hypothesis of no association cannot be rejected in three cases, that is, in connection with the Nasdaq, FTSE, and S\&P500. But this global period covers both a period of strong market increases, that is, the dot-com bubble, and a crisis period as sparked by the subprime episode. Therefore, we calculate statistics for the two sub periods, 1994-2002 and 2007-2011.

During the former dot-com bubble period, we find higher coefficients/associations between European markets, with coefficients between 0.36 and 0.46 , whereas the coefficients between US markets and European markets are lower, between 0.14 for the $\mathrm{DJ} / \mathrm{DAX}$ and 0.37 for the CAC/S\&P500. In addition, we note that the association is not different from 0 between the Nikkei and all other markets except the Dow Jones (0.14).

In contrast, the subprime crisis period presents several different features. First, the tests suggest rejecting the null hypothesis of no association. Second, the "correlations" among European markets are very high, including 0.56 between DAX and CAC, and 0.50 among theses two markets indices and FTSE. Third, the association coefficients between the Nikkei and other indices are no longer null with values between 0.20 and 0.32 with the DAX, CAC, FTSE, and DJ, and around 0.14 with the Nasdaq and S\&P500.

(INSERT table 3) 


\section{Conclusion}

We propose a method to detect the abnormal states in stock market returns. We study seven indices, over the period January 1991 (first week) - December 2011 (third week). We estimate three possible states: a high rate of return and a low return, both to which constitute abnormal returns with high volatility, and an intermediate state. To determine the state of the markets at each date, we have estimated the parameters of the return process using MCMC method (Metropolis-Hastings algorithm). With Cramer's V coefficient, we deduce the association coefficients or "correlations" among the different states of the major stock exchange markets around the world. First, we show that the associations are globally stronger during the subprime crisis than during the dot-com bubble period. Second, among European markets, we obtain higher Cramer's V, regardless of the period. Third, the association between the Nikkei and the other markets indices is systematically lower, confirming a relative disconnection of the Japanese market from other developed economy markets. 


\section{References}

[1] Bollerslev, T. : Generalized Autoregressive Conditional Heteroskedasticity, Journal of Econometrics 31, pp. 307-327, 1986

[2] Brown, S.J. and Warner, J.B. : Measuring Security Price Abnormal Performance, Journal of Financial Economics 8, pp. 295-297, 1980.

[3] Brown, S.J. and Warner, J.B. : Using Daily Stock Returns: The Case of Event Studies, Journal of Financial Economics 14, pp. 3-12, 1985.

[4] Cai, J. : A Markov Model of Switching-Regime ARCH, Journal of Business and Economic Statistics, 12, pp. 309-316, 1994

[5] S. Chib, E. Greenberg : Understanding the Metropolis-Hastings Algorithm, The American Statistician, 49, pp. 327-335, 1995.

[6] S. Chib, S. Ramamurthy : Tailored randomized block MCMC methods with application to DSGE models, Journal of Econometrics, 155, pp.19-38., 2010.

[7] Cont, R. : Empirical Properties of Asset Returns: Stylized Facts and Statistical Issues, Quantitative Finance, 1, p. 223-236., 2001.

[8] Cumperayot, P., Keijzer, T., Kouwenberg, R. : Linkages between extreme stock market and currency returns, . Journal of International Money and Finance 25 (3), pp. 528-550, 2006.

[9] Dueker, M. J. : Markov Switching in GARCH Processes and Mean-Reverting Stock-Market Volatility, Journal of Business and Economic Statistics, American Statistical Association, 15(1), pp. 26-34, 1997

[10] Engle, R.F. : Autoregressive Conditional Heteroscedasticity with Estimates of the Variance of UK Inflation, Econometrica, 50, 98\%-100\%, 1982.

[11] Embrechts, P., A. McNeil and D. Straumann : Correlation and Dependence Properties in Risk Management: Properties and Pitfalls, in M. Dempster, ed., Risk Management: Value at Risk and Beyond, Cambridge University Press, 2002.

[12] El Karoui, N. : Mesure et couverture des risques dans les marchés financiers, Matapli, 69, pp. 43-66, 2002.

[13] Hahn, M., S. Frühwirth-Schnatter and J. Sass : Markov chain Monte-Carlo methods for parameter estimation in multidimensional continuous time Markov switching models, Journal of Financial Econometrics, 8(1), pp. 88-121, 2010.

[14] Hahn, M. and Hunt : Estimation and calibration of continuous-time semi-Markov switching model ISBA 2010.

[15] Hamilton, J. D. and Susmel, R. : Autoregressive Conditional Heteroscedasticity and Changes in Regime, Journal of Econometrics, 64, pp. 307-333, 1994. 
[16] Hayashi, F., and Prescott, E. C. : The 1990s in Japan: a lost decade, Review of Economic Dynamics 5, pp. 206-235, 2002.

[17] Fama, E. F. and K. R. French : Common risk factors in returns on stocks and bonds, Journal of Financial Economics, 33, pp. 3-56, 1993.

[18] Kaufmann, S. and Fruhwirth-Schnatter, S. : Bayesian Analysis of Switching Arch Models, Journal of Time Series Analysis, 23(4), pp. 425-458, 2002.

[19] King, M., E. Santana and S. Wadhwani : Volatility and Links Between National Stock Markets, Econometrica, 62(4), pp. 901-933, 1994.

[20] King, M., E. and S. Wadhwani : Transmission of Volatility Between Stock Markets, The Review of Financial Studies, 3, 1, pp. 5-33, 1990.

[21] M. Richey : The Evolution of Markov Monte Carlo Chain Methods, The American Mathematical Monthly, 117(5), pp. 383-413, 2002.

[22] Schaller, H. and Van Norden, S. : Regime Switching in Stock Market Returns, Applied Financial Economics, 7, pp. 177-191, 1997.

[23] S. L. Scott : Bayesian Methods for Hidden Markov Models: Recursive Computing in the 21st Century, Journal of American Statistical Association, 97(457), pp.337351, 2002.

[24] Wishart, J. : The generalised product moment distribution in samples from a normal multivariate population, Biometrika 20A, 1928.

[25] Ziobrowski, A. J., Cheng P., Boyd, J. W. and B. J. Ziobrowski : Abnormal returns from the common stock investments of the U. S. Senate, Journal of Financial and Quantitative Analysis 39(4), pp. 661-676, 2004. 

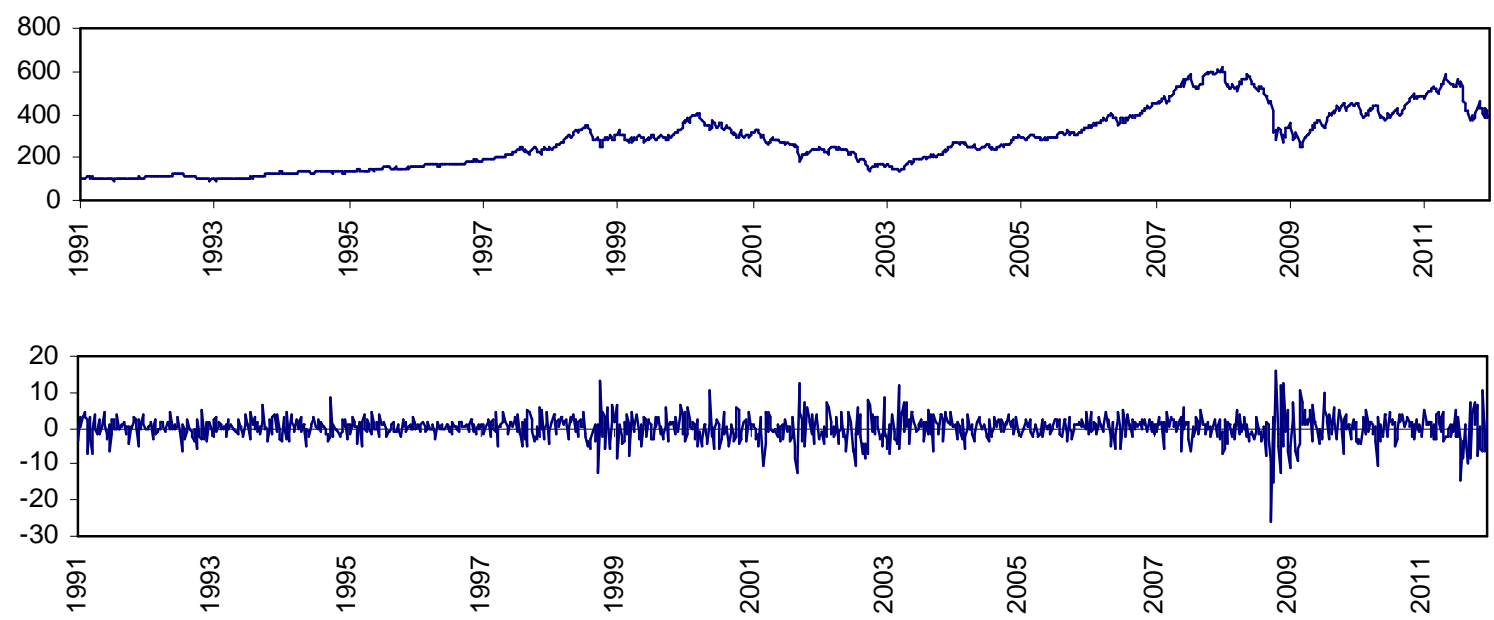

Figure 1: DAX quotes (top) and weekly returns (bottom) 12/31/1991-12/19/2011
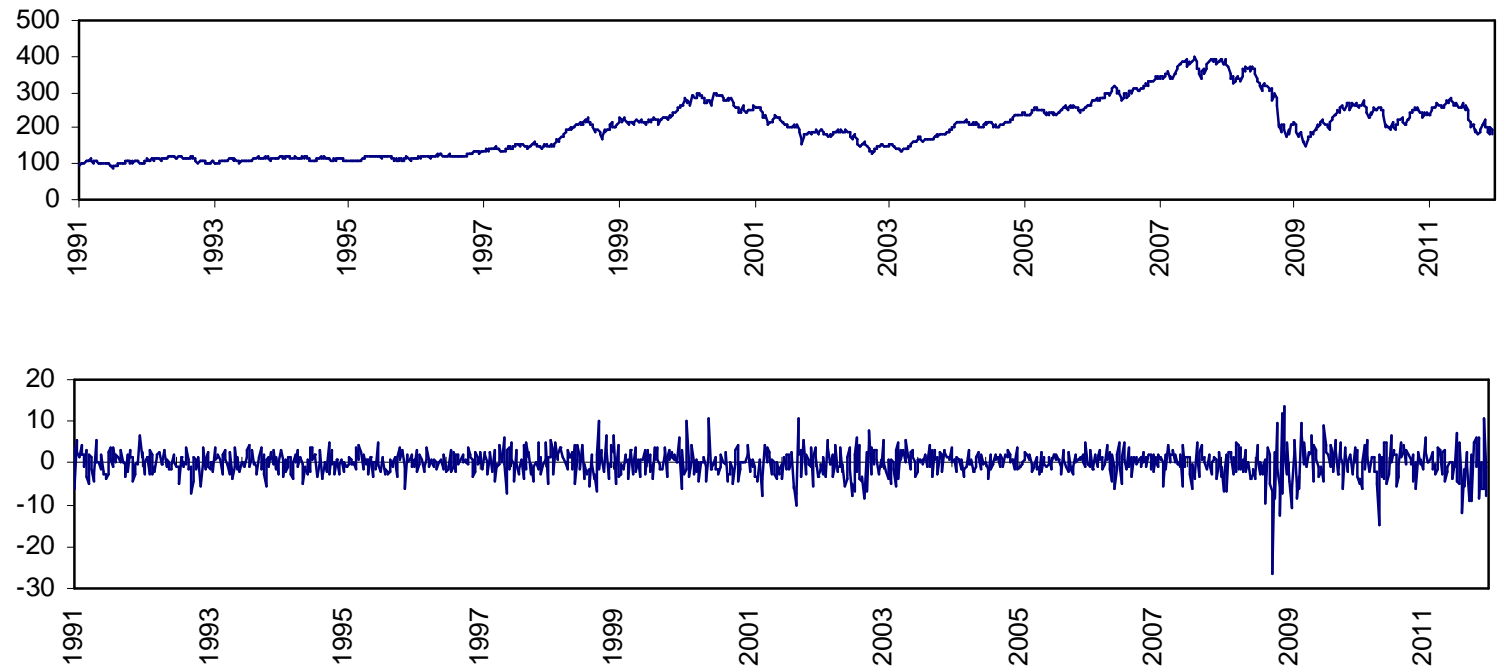

Figure 2: CAC40 quotes (top) and weekly returns (bottom) 12/31/1991-12/19/2011
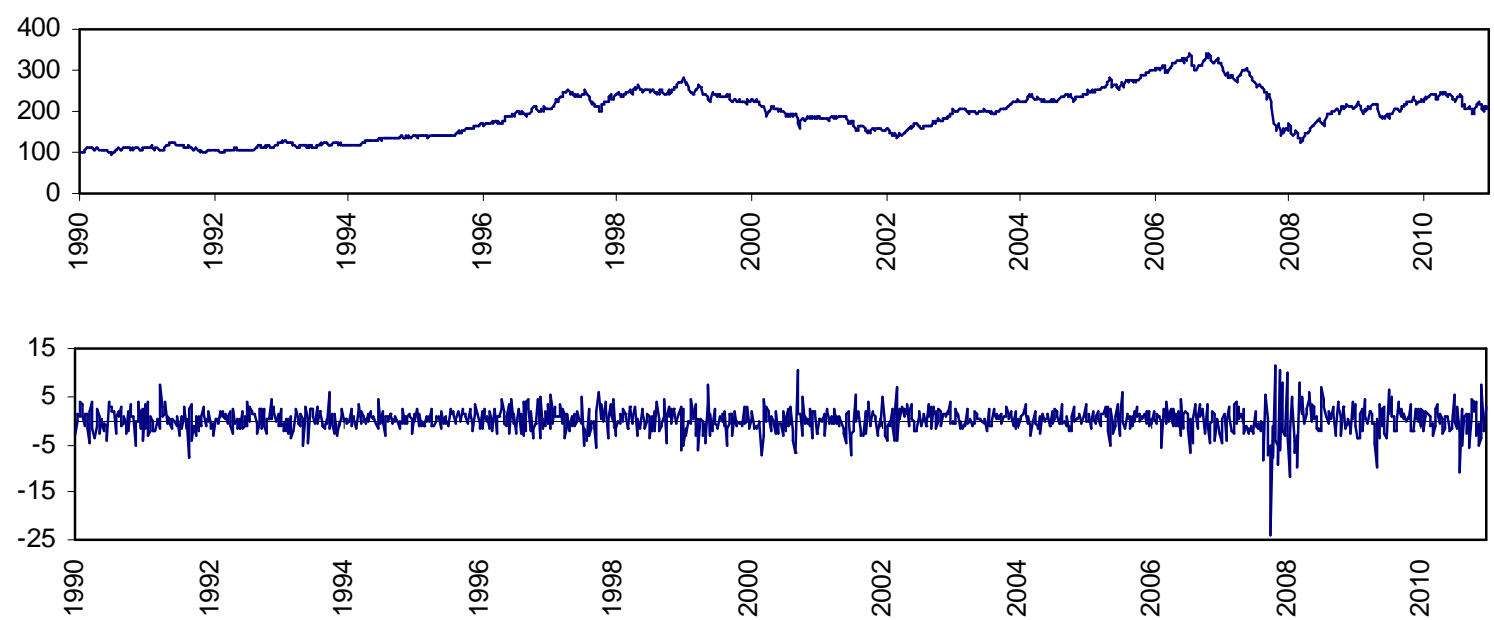

Figure 3: FTSE quotes (top) and weekly returns (bottom) 12/31/1990-12/19/2011 

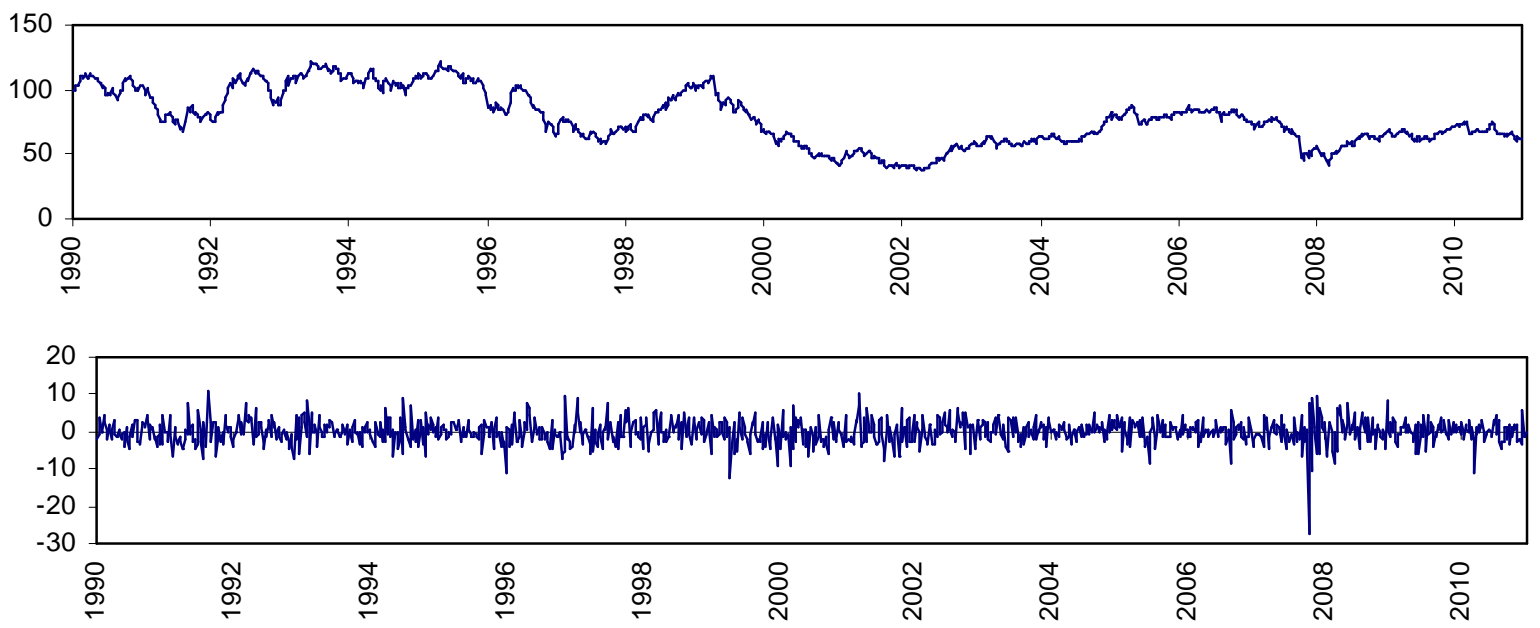

Figure 4: NIKKEI quotes (top) and weekly returns (bottom) 12/31/1990-12/19/2011
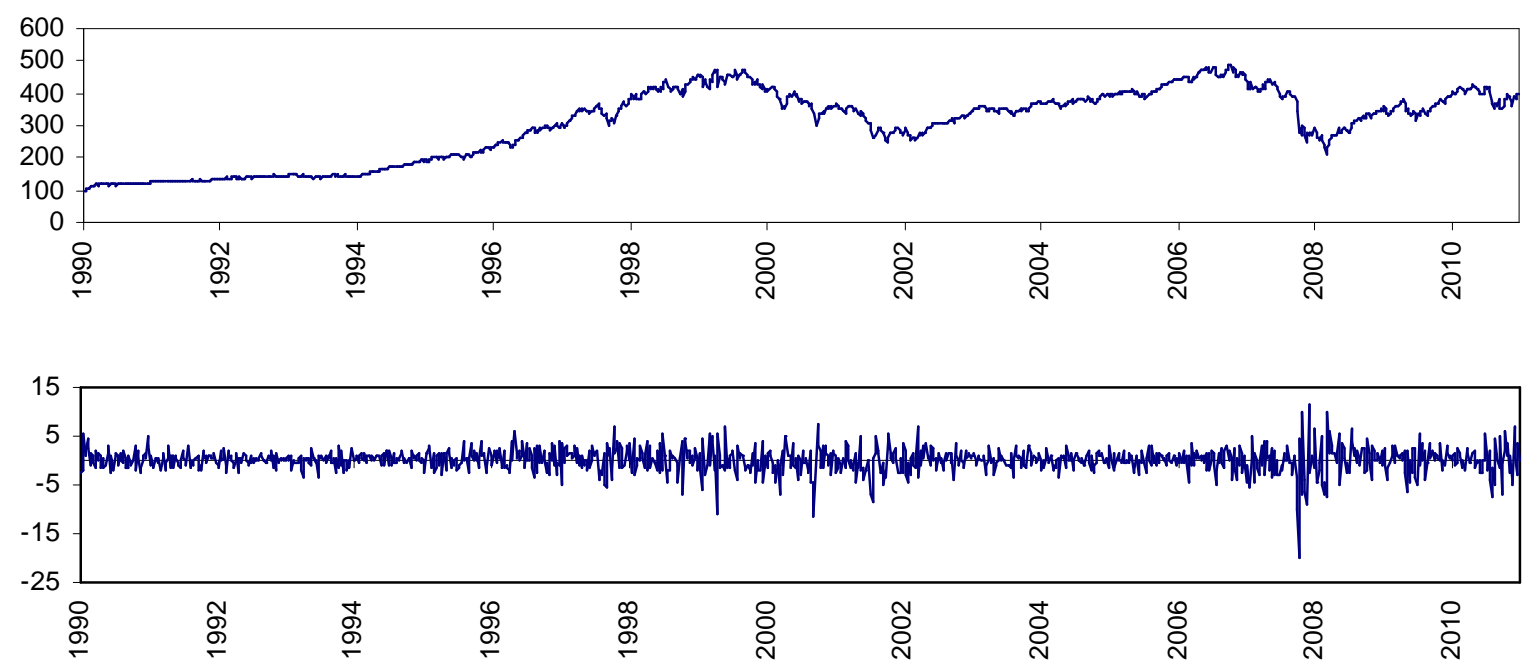

Figure 5: S\&P500 quotes (top) and weekly returns (bottom) 12/31/1990-12/19/2011
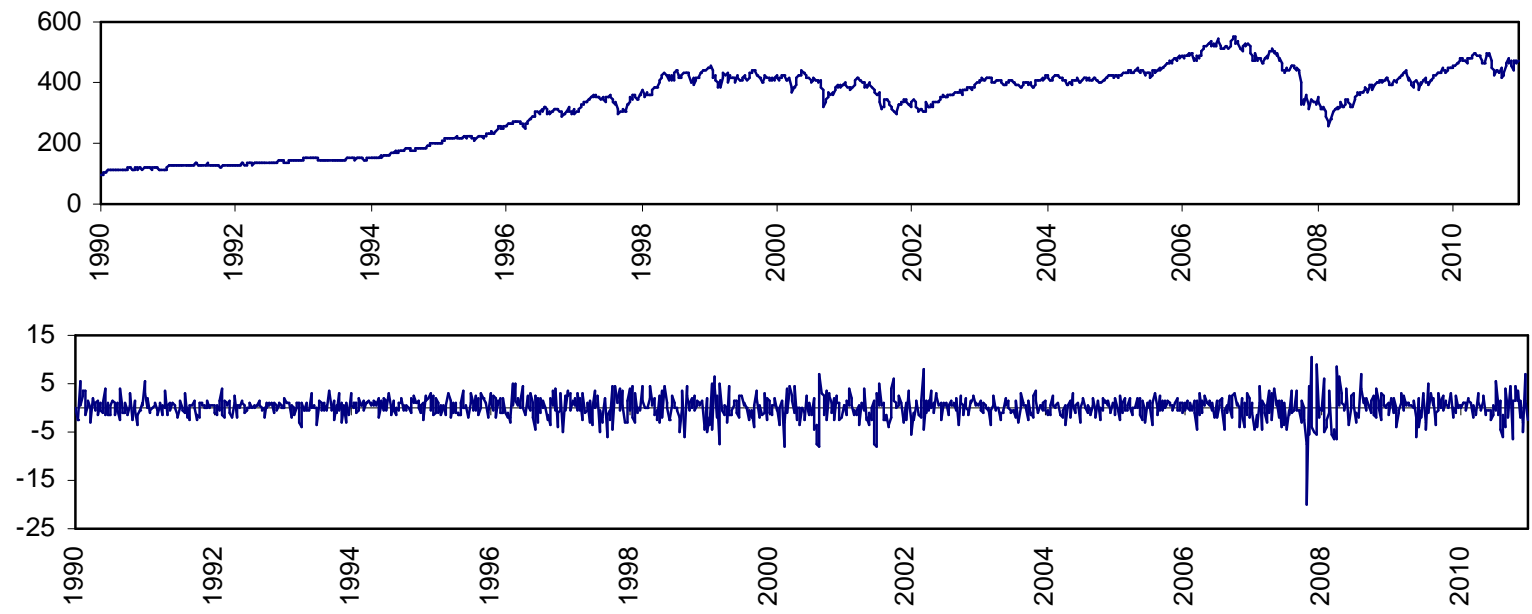

Figure 6: Dow Jones quotes (top) and weekly returns (bottom) 12/31/1990-12/19/2011 

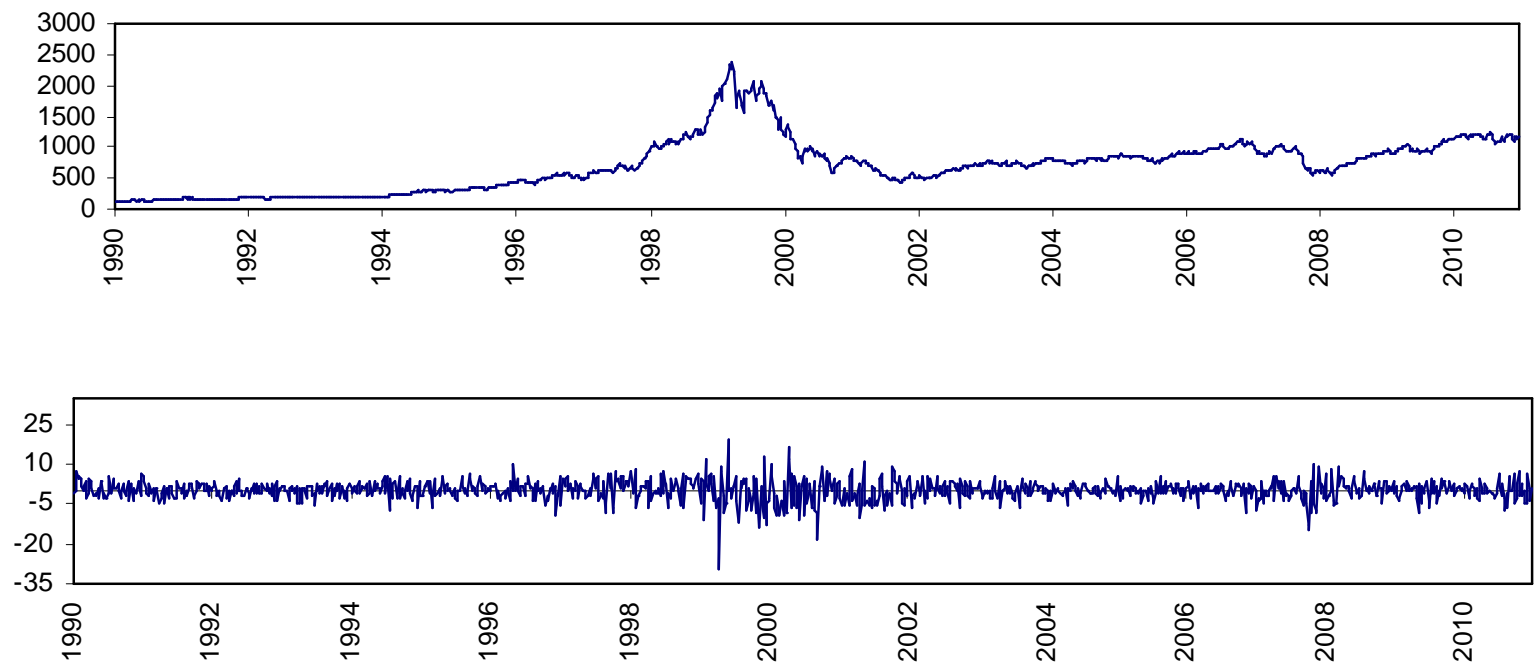

Figure 7: Nasdaq quotes (top) and weekly returns (bottom) 12/31/1990-12/19/2011 

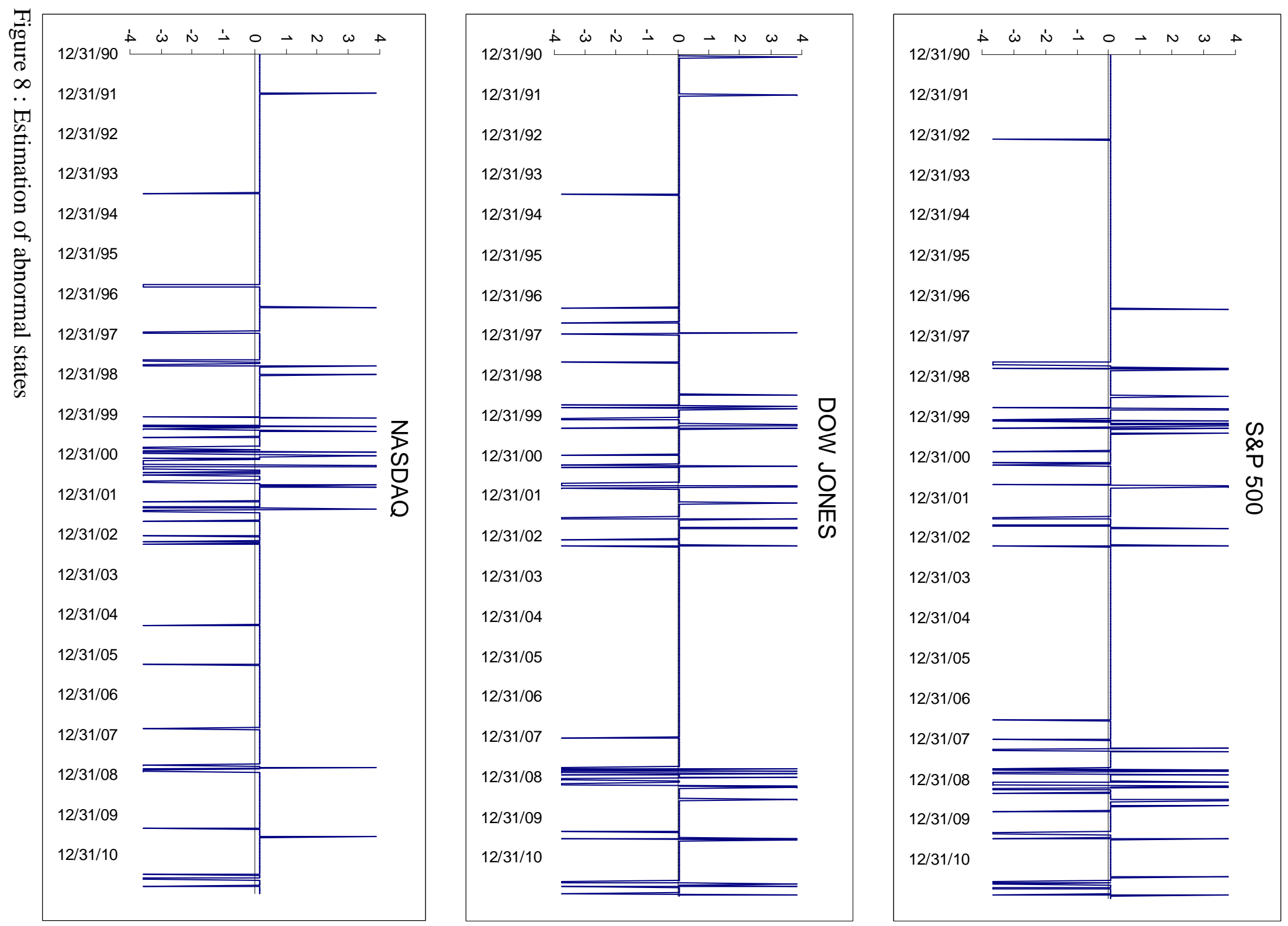

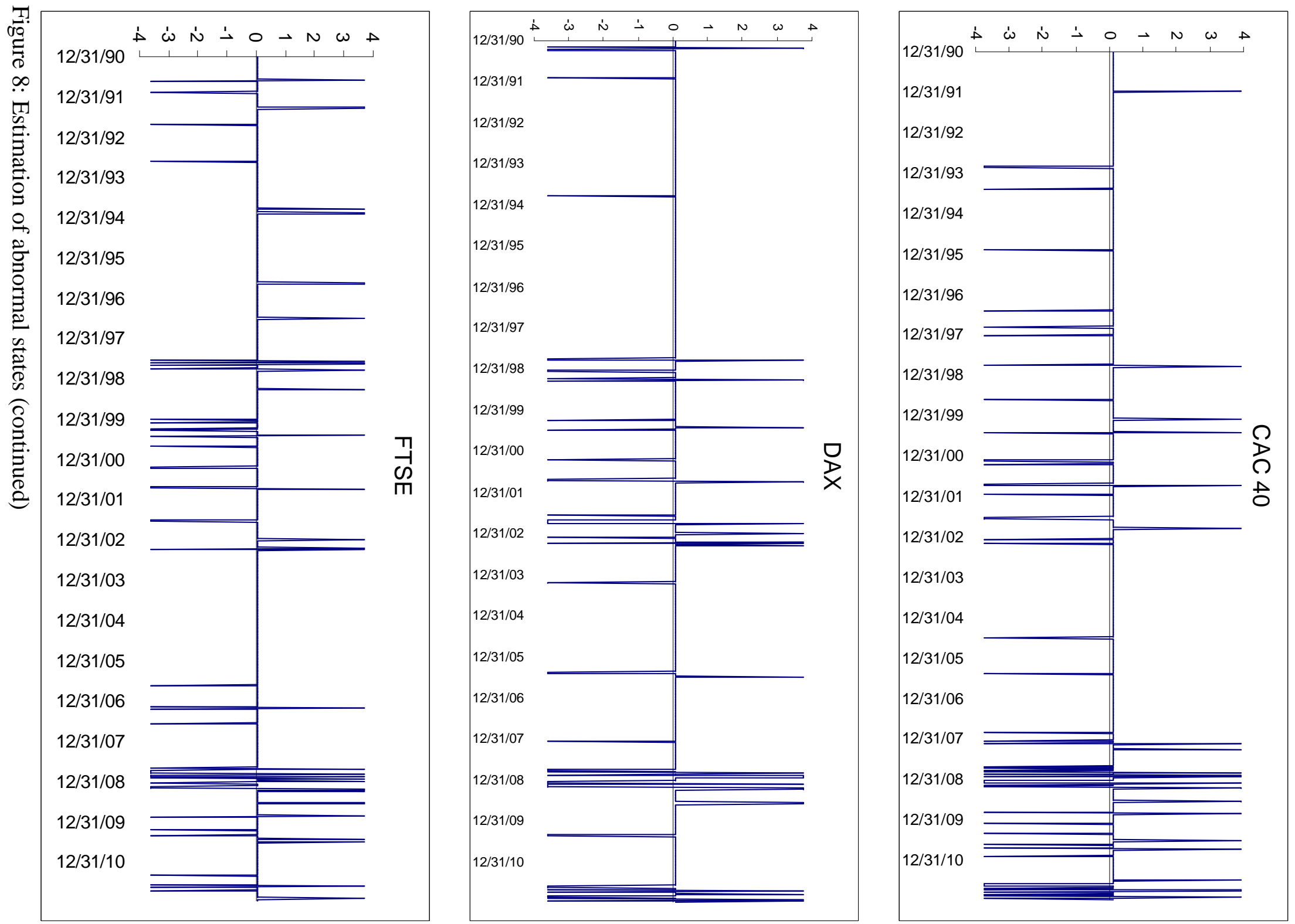


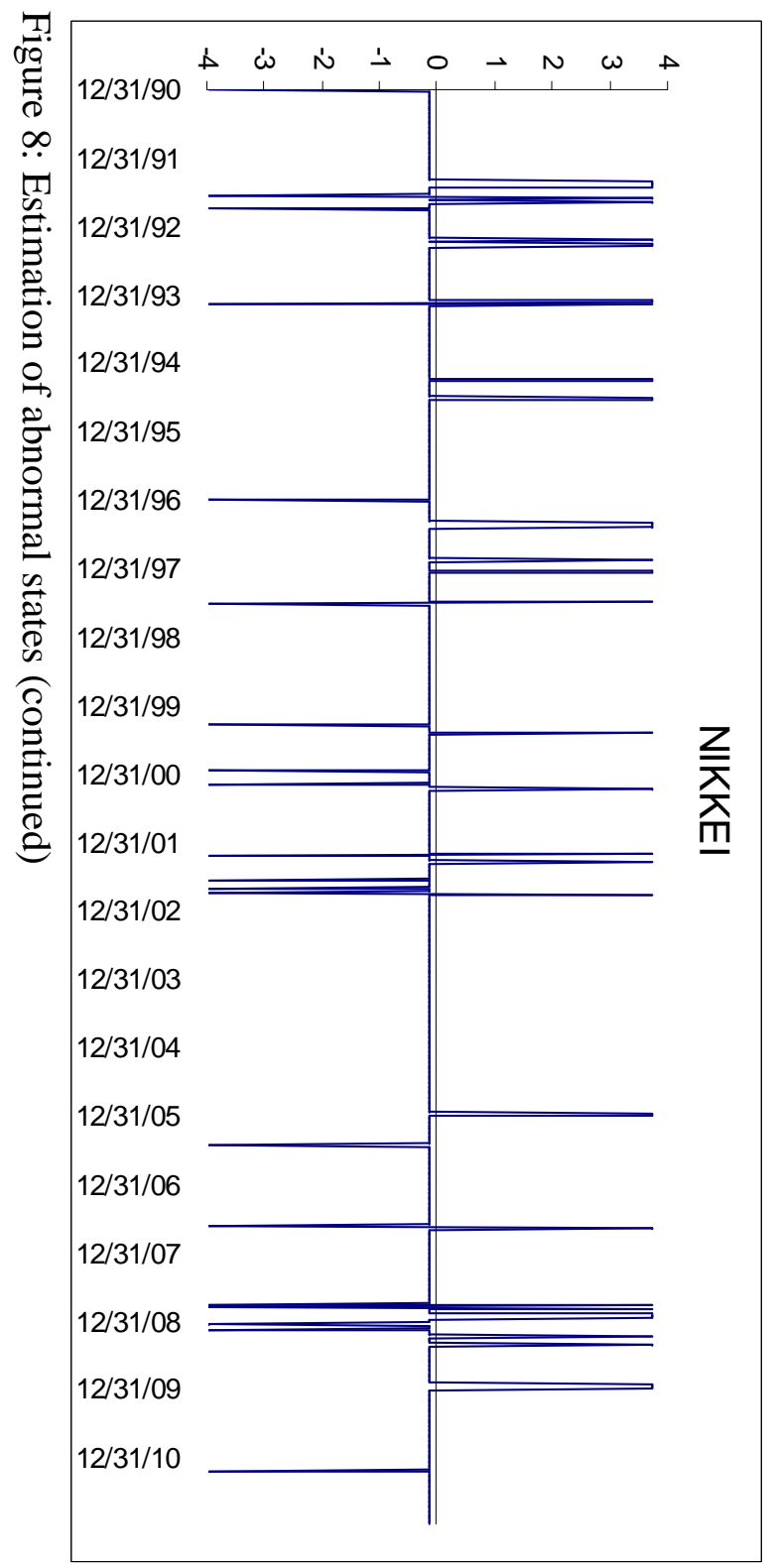


Table1 : Summary statistics of stock returns (x100)

Period 12/31/1990-12/25/2011

\begin{tabular}{lccccccc}
\hline \multicolumn{1}{c}{ Statistic } & DAX & CAC40 & FTSE & NIKKEI & S\&P500 & $\begin{array}{c}\text { Dow } \\
\text { Jones }\end{array}$ & Nasdaq \\
\hline \hline Mean & 0.1275 & 0.0617 & 0.0662 & -0.0464 & 0.1231 & 0.1374 & 0.2219 \\
Min & 0.4510 & 0.2917 & 0.2075 & -0.0382 & 0.2308 & 0.2717 & 0.3813 \\
Max & 15.7056 & 13.6505 & 11.2940 & 11.1067 & 11.3559 & 10.7449 & 19.1400 \\
Median & -25.6135 & -26.3169 & -24.0127 & -27.4312 & -20.0837 & -19.8692 & -29.1008 \\
Std. Dev. & 3.3519 & 3.1616 & 2.5966 & 3.1897 & 2.4125 & 2.3299 & 3.7327 \\
Skewness & -0.6078 & -0.7030 & -0.8640 & -0.5456 & -0.7305 & -0.6648 & -0.6193 \\
Kurtosis & 8.1653 & 8.7015 & 11.35396 & 8.2784 & 9.6639 & 9.0267 & 8.3408 \\
Jarque-Bera & $1284.73^{*}$ & $1573.35^{*}$ & $3320.35^{*}$ & $1325.54^{*}$ & $2123.55^{*}$ & $1737.85^{*}$ & $1371.41^{*}$ \\
Test (a) & $(0.000)$ & $(0.000)$ & $(0.000)$ & $(0.000)$ & $(0.000)$ & $(0.000)$ & $(0.000)$ \\
\hline Obs. & 1095 & 1095 & 1095 & 1095 & 1095 & 1095 & 1095 \\
\hline \hline
\end{tabular}

(a) p-values are in parentheses. * indicates the rejection of the null hypothesis of a normal distribution 
Table 2: Transition Matrices of States

\begin{tabular}{|c|c|c|c|c|}
\hline \multirow{4}{*}{ Dow Jones } & & Low State 1 & Int. State 2 & High State 3 \\
\hline & S1 & 0.3600328 & 0.3922399 & 0.2477273 \\
\hline & S2 & 0.0543472 & 0.9078343 & 0.0378185 \\
\hline & S3 & 0.3500569 & 0.3266098 & 0.3233333 \\
\hline \multirow[t]{3}{*}{ SP 500} & S1 & 0.4117325 & 0.3760589 & 0.2122086 \\
\hline & $\mathrm{S} 2$ & 0.0501945 & 0.9069498 & 0.0428557 \\
\hline & S3 & 0.2844652 & 0.3443377 & 0.3711971 \\
\hline \multirow[t]{3}{*}{ Nasdaq } & $\mathrm{S} 1$ & 0.4286232 & 0.3271078 & 0.2442690 \\
\hline & $\mathrm{S} 2$ & 0.0723289 & 0.9067297 & 0.0209414 \\
\hline & S3 & 0.3091477 & 0.4306618 & 0.2601905 \\
\hline \multirow[t]{3}{*}{ FTSE } & S1 & 0.3097893 & 0.3901177 & 0.3000930 \\
\hline & S2 & 0.0529152 & 0.9053966 & 0.0416882 \\
\hline & S3 & 0.2548288 & 0.3616358 & 0.3835354 \\
\hline \multirow[t]{3}{*}{ NIKKEI } & S1 & 0.2244978 & 0.5685314 & 0.2069708 \\
\hline & S2 & 0.0269065 & 0.9149763 & 0.0581172 \\
\hline & S3 & 0.2109083 & 0.2309196 & 0.5581721 \\
\hline \multirow[t]{3}{*}{ CAC } & S1 & 0.3184206 & 0.4178978 & 0.2636816 \\
\hline & S2 & 0.0780773 & 0.8912417 & 0.0306810 \\
\hline & S3 & 0.3374663 & 0.4571611 & 0.2053726 \\
\hline \multirow[t]{3}{*}{ DAX } & S1 & 0.4191528 & 0.3240655 & 0.2567818 \\
\hline & $\mathrm{S} 2$ & 0.0564527 & 0.9119077 & 0.0316397 \\
\hline & S3 & 0.2829299 & 0.3923040 & 0.3247660 \\
\hline
\end{tabular}

Note: S1, Low State; S2, Intermediate State; S3, High State. 
Table 3: Measure of association between states of markets: Cramer's V

Global period: 12/31/1990-12/25/2011

\begin{tabular}{lccccccc}
\hline \hline Index & DJ & S\&P500 & NASDAQ & FTSE & NIKKEI & DAX & CAC \\
\hline DJ & & & & & & & \\
S\&P500 & 0.2311 & & & & & & \\
NASDAQ & 0.2193 & 0.1750 & & & & \\
FTSE & 0.2492 & 0.2380 & 0.1622 & & & \\
NIKKEI & 0.1395 & $0.0782^{*}$ & $0.0760^{*}$ & $0.0851^{*}$ & & \\
DAX & 0.2567 & 0.2506 & 0.1344 & 0.4020 & 0.1884 & & \\
CAC & 0.2393 & 0.2070 & 0.1917 & 0.3951 & 0.1260 & 0.4269 & \\
\hline \hline
\end{tabular}

Dot-com bubble period: 05/12/1994 - 09/30/2002

\begin{tabular}{lccccccc}
\hline \hline Index & DJ & S\&P500 & NASDAQ & FTSE & NIKKEI & DAX & CAC \\
\hline DJ & & & & & & & \\
S\&P500 & 0.2442 & & & & & & \\
NASDAQ & 0.2275 & 0.2515 & & & & \\
FTSE & 0.1715 & 0.2500 & 0.1269 & & & \\
NIKKEI & 0.1431 & $0.0836^{*}$ & $0.1010^{*}$ & $0.0379^{*}$ & & \\
DAX & 0.1435 & 0.3202 & $0.1041^{*}$ & 0.3633 & 0.1572 & & \\
CAC & 0.1873 & 0.3755 & 0.2020 & 0.4151 & $0.0827^{*}$ & 0.4641 & \\
\hline \hline
\end{tabular}

Subprime and euro crisis period: 07/09/2007 - 12/25/2011

\begin{tabular}{lccccccc}
\hline \hline Index & DJ & S\&P500 & NASDAQ & FTSE & NIKKEI & DAX & CAC \\
\hline DJ & & & & & & & \\
S\&P500 & 0.2279 & & & & & & \\
NASDAQ & 0.2756 & 0.1548 & & & & & \\
FTSE & 0.3747 & 0.2573 & 0.3137 & & & & \\
NIKKEI & 0.2020 & 0.1448 & 0.1413 & 0.2278 & & \\
DAX & 0.4038 & 0.2943 & 0.2903 & 0.4941 & 0.3231 & & \\
CAC & 0.2922 & 0.1903 & 0.3050 & 0.4943 & 0.2382 & 0.5625 & \\
\hline \hline
\end{tabular}

Note: * indicates that the null hypothesis, i.e. independence between the variables/states, is not rejected $\left(\chi^{2}\right.$ statistic) at the 5\% level. 